\title{
NILAI-NILAI KEARIFAN BUDAYA LOKAL ORANG RIMBA (Studi pada Suku Minoritas Rimba di Kecamatan Air Hitam Provinsi Jambi)
}

\author{
Takiddin \\ Universitas Islam Negeri (UIN) Syarif Hidayatullah Jakarta \\ Email: takiddin@gmail.com
}

\begin{abstract}
This article was written to provide an overview of the values of local wisdom in the culture of Orang Rimba (Jungle People) in Black Water District Sarolangun Jambi Province. To obtain the data in question, the author conducted research by coducting interview, observation and study of literature. Orang Rimba have lifestyles and beliefs that are unique and different from the life of modern society. They looked at the forest as their residence. One belief of Orang Rimba is if there are people who died at their residence, then it is considered as an area harmful and they have to find a new place. This habit is called "Melangun". This belief is the main factor that affect the Orang Rimba not settled. Orang Rimba tribe regarded as backward, primitive and easily manipulated. However, if studied carrefully, Orang Rimba have so much values for us to learn, especially in their behavior with regards to natural preservation.
\end{abstract}

Keywords: local wisdom, Orang Rimba

\begin{abstract}
Abstrak
Artikel ini ditulis untuk memberikan gambaran tentang nilai-nilai kearifan lokal dalam budaya Orang Rimba di Kecamatan Air Hitam, Kabupaten Sarolangun, Provinsi Jambi. Guna memperoleh data yang dimaksud, penulis melakukan penelitian dengan teknik wawancara, observasi dan kajian kepustakaan. Orang Rimba memiliki gaya hidup dan kepercayaan yang unik dan berbeda dari kehidupan masyarakat modern. Mereka memandang hutan sebagai tempat tinggal mereka. Salah satu kepercayaan Orang Rimba adalah jika ada orang yang meninggal dunia di tempat tinggal mereka, maka tempat itu dianggap sebagai daerah yang celaka bagi mereka dan mereka harus mencari tempat yang baru yang disebut "melangun". Kepercayaan inilah yang menjadi faktor utama yang mempengaruhi proses kehidupan Orang Rimba tidak menetap. Orang Rimba dianggap sebagai suku yang terbelakang, primitif, dan mudah dipermainkan. Namun, jika dipelajari dengan baik kandungan nilai dari budaya Orang Rimba ini banyak sekali terutama dalam perilaku mereka dalam menjaga kelestarian alam.
\end{abstract}

Kata kunci: kearifan lokal, Orang Rimba

\section{A. Pendahuluan}

Di Sumatera terdapat sejumlah suku-suku besar yang mempunyai ciri khas tradisional. Suku yang terkenal aantara lain Aceh, Batak, Minangkabau, dan Melayu. Selain itu terdapat pula beberapa suku minoritas yang mendiami beberapa daerah di Sumatera, terutama di daerah hutan luas, di antara sungai-sungai besar, di sekitar rawa-rawa, maupun di pulau-pulau lepas pantai. Salah satu suku minoritas tersebut adalah suku anak dalam (SAD) atau biasa juga disebut sebagai Orang Rimba. Orang Rimba adalah salah satu suku bangsa minoritas yang hidup di Pulau Sumatera, tepatnya di Provinsi Jambi dan Sumatera Selatan. Mereka mayoritas hidup di propinsi Jambi, dengan perkiraan jumlah populasi sekitar 3.198 orang. ${ }^{1}$

Suku Anak Dalam (SAD) yang di dalam tulisan ini lebih sering menggunakan sebutan Orang Rimba memiliki gaya hidup dan kepercayaan yang unik dan berbeda dari kehidupan masyarakat modern. Mereka

Ibrahim, Kehidupan Suku Anak Dalam di Kecamatan Air Hitam Kabupaten Sarolangun, Jurnal Antologi Geografi Jurusan Pendidikan Geografi Universitas Pendidikan Indonesia, Volume 1, Nomor 3, Edisi Desember 2013. 
memandang hutan sebagai tempat tinggal mereka. Mereka adalah bagian penting dari hutan itu sendiri. Orang Rimba sangat menggantungkan hidupnya pada hutan. Oleh karena itu, mereka sangat menjaga kelestarian hutan. Mereka mempunyai persepsi bahwa hutan adalah milik bersama, sehingga siapapun boleh memanfaatkannya. Orang Rimba tidak ingin hutan musnah karena hutan itu sendiri adalah rumah mereka. Sementara itu, karena faktor ekonomi dan desakan kebutuhan akan ladang dan kayu, tidak sedikit kalangan yang terusmenerus merusak hutan dengan cara menebang pohon dan membuka ladang. Kegiatan seperti itu tentu sangat mengancam keberadaan hutan Taman Nasional Bukit Duabelas di Kabupaten Sarolangun, di mana Orang Rimba tinggal.

Orang Rimba memiliki kebiasaan-kebiasaan yang berbeda dari masyarakat Melayu pada umumnya. Orang Rimba mengenal istilah budaya yang menurut orang dari suku lain terasa aneh dan tertinggal. Tidak heran jika Orang Rimba dipandang sebelah mata oleh orang terang (Melayu). Mereka dianggap masih memiliki budaya yang sangat primitif. Akan tetapi, jika disimak secara seksama, sebenarnya kandungan nilai dari budaya Orang Rimba ini banyak sekali. Bahkan di beberapa sisi Orang Rimba memiliki pemikiran yang cukup maju, terutama dalam menjaga kelestarian alam.

Berdasarkan uraian di atas, maka penelitian ini dilaksanakan untuk memperoleh gambaran tentang nilai-nilai kearifan lokal dalam budaya Orang Rimba di Kecamatan Air Hitam, Kabupaten Sarolangun, Provinsi Jambi, serta implementasinya dalam kehidupan sehari-hari.

\section{B. Landasan Teori}

\section{Kearifan Lokal}

Kearifan lokal menurut UU No.32/2009 tentang Perlindungan dan Pengelolaan Lingkungan Hidup BAB I Pasal 1 butir 30 adalah nilai-nilai luhur yang berlaku dalam tata kehidupan masyarakat untuk melindungi dan mengelola lingkungan hidup secara lestari. ${ }^{2}$ Dalam pengertian kebahasaan, kearifan lokal berarti kearifan setempat (local wisdom) yang dapat dipahami sebagai gagasan-gagasan lokal yang

2 Undang-undang RI No. 32 Tahun 2009 tentang Perlindungan dan Pengelolaa Lingkungan Hidup. bersifat bijaksana, penuh kearifan, bernilai yang tertanam dan diikuti oleh warga masyarakatnya. Dalam konsep antropologi, kearifan lokal dikenal pula sebagai pengetahuan setempat (indigenous or local knowledge), atau kecerdasan setempat (local genius), yang menjadi dasar identitas kebudayaan (cultural identity). ${ }^{3}$ Dapat dikatakan bahwa kearifan lokal adalah nilainilai luhur yang berlaku dalam tata kehidupan masyarakat berupa gagasan-gagasan lokal yang bersifat bijaksana, penuh kearifan, bernilai yang tertanam dan diikuti oleh warga masyarakatnya untuk melindungi dan mengelola lingkungan hidup secara lestari.

\section{Orang Rimba}

Orang Rimba adalah salah satu suku bangsa minoritas yang hidup di Pulau Sumatera, tepatnya di Provinsi Jambi dan Sumatera Selatan. Mereka mayoritas hidup di provinsi Jambi, dengan perkiraan jumlah populasi sekitar 3.198 orang. Menurut tradisi lisan, suku Anak Dalam merupakan orang Maalau Sesat (orang yang tersasar), yang lari ke hutan rimba di sekitar Air Hitam, Taman Nasional Bukit Duabelas. Mereka kemudian dinamakan Moyang Segayo. Tradisi lain menyebutkan mereka berasal dari Pagaruyung, yang mengungsi ke Jambi.

Secara ekologis, Orang Rimba hidup tersebar di tiga wilayah berbeda, yaitu: (1) di bagian barat Provinsi Jambi (sekitar jalan lintas timur Sumatera), (2) kawasan Taman Nasional (TN) Bukit Duabelas, dan (3) tinggal di bagian utara Provinsi Jambi, terutama di Taman Nasional Bukit Tigapuluh (berada di perbatasan Riau dan Jambi). Orang Rimba yang hidup di kawasan Bukit Duabelas berdiam dan mengembara di hutan dataran rendah antara sungai Batanghari dan Sungai Tembesi. Mereka hidup di antara anak sungai yang ada di kawasan Bukit Duabelas tersebut.

Temenggung Tarib dalam Johan menceritakan bahwa menurut sejarah lisan orang Rimba, yang hidup di Taman Nasional Bukit Duabelas, berasal dari kerajaan Pagaruyung yang merantau ke Jambi. Temenggung Tarib menjelaskan bahwa dia bisa menceritakan silsilah keluarga sampai kepada 6 (enam) generasi yang

Nasruddin, dkk, Kearifan Lokal di Tengah Modernisasi, Jakarta, Pusat Penelitian dan Pengembangan Kebudayaan Badan Pengembangan Sumber Daya Kebudayaan dan Pariwisata Kementerian Kebudayaan dan Pariwisata Republik Indonesia, 2011. 
lalu. ${ }^{4}$ Ahli antropolog Jambi menjelaskan bahwa kelompok yang tinggal bersama Temenggung Tarib menceritakan bahwa menurut sejarah lisan orang Rimba itu, mereka bisa menceritakan silsilah sejarah dari nenek moyangnya sampai 10 (sepuluh) generasi. Artinya, orang Rimba memiliki sejarah lisan dalam jangka 300 sampai 500 tahun, atau kurang lebih dari abad k-16 atau ke- $17 . .^{5}$

\section{Asal Muasal Orang Rimba}

Berdasarkan cerita tutur setiap kelompok, ada berbagai versi cerita yang berkaitan dengan asal-usul Orang Rimba. Orang Rimba Sungai Mekekal, misalnya, mengaku bernenek moyang yang sama dengan orang Melayu di Tanah Garo, yaitu berasal dari buah gelumpang. Orang Rimba Air Hitam mengatakan sebagai keturunan orang-orang desa yang lari ke dalam hutan. Sementara itu Orang Rimba yang berada di barat Provinsi Jambi mengaku berasal dari Orang Rimba di Sumatera Selatan (Musi Rawas) yang mempunyai sejarah asal-usul sama dengan orang Melayu yang melarikan diri ke dalam hutan karena penjajahan. Adapun Orang Rimba yang berada di kawasan Taman Nasional Bukit Tigapuluh mengatakan mereka berasal dari Orang Rimba Kuamang Kuning dan Rimbo Bujang, daerah Jambi yang berbatasan dengan Sumatera Barat. ${ }^{6}$

Apabila ditelisik, berbagai versi cerita yang dapat dikelompokkan ke dalam tiga versi tersebut memiliki kesamaan tent8ang asal usul orang rimba, yakni mereka berasal dari suku bangsa lain, baik suku bangsa Melayu maupun suku bangsa Minangkabau.

\section{Agama Orang Rimba}

Anthony F.C. Wallace dalam Haviland mendefinisikan agama sebagai seperangkat upacara, yang diberi rasionalisasi mitos, dan yang menggerakkan kekuatan-kekuatan supernatural dengan maksud untuk mencapai atau untuk menghindarkan sesuatu perubahan keadaan manusia atau alam. ${ }^{7}$ Banyak agama memiliki narasi, simbol, dan sejarah suci yang dimaksudkan untuk menjelaskan makna hidup

\footnotetext{
4 Johan, Organisasi Sosial dan Kebudayaan Kelompok Minoritas Indonesia. Makalah pada Program Studi Indonesia Kerjasama Pendidikan Tersier Indonesia - Australia Universitas Gadjah Mada Yogyakarta, 2003. hal.39

5 Ibid, h.39.

Prasetijo, Adi, Serah Jajah dan Perlawanan yang Tersisa: Etnograf Orang Rimba di Jambi. Jakarta: Wedatama Widya Sastra. h. 46.

7 Haviland, William A, Antropologi; jilid 2 Jakarta: Erlangga, 1985
}

dan untuk menjelaskan asal-usul kehidupan atau alam semesta. Dari keyakinan mereka tentang kosmos dan sifat manusia, orang memperoleh moralitas, etika, hukum agama atau gaya hidup yang disukai.

Orang Rimba percaya adanya Tuhan, namun wujud dan gambaran Tuhan sangat abstrak. ${ }^{8}$ Mereka berkeyakinan adanya makhluk halus yang ada di dunia, yang dapat berupa dewa, arwah orang yang sudah meninggal, yang mereka sebut sebagai malaikot dan silom atau siluman. Dewa-dewa, malaikot, dan silom hidup dalam dunia ghaib yang mereka sebut dengan halom dewo. Dewa dan Dewo ini mereka sebut degan istilah orang.

\section{Budaya Orang Rimba}

Jika dipahami dari istilah dalam bahasa Indonesia, kata budaya berasal dari bahasa sanskerta, buddhayah yang merupakan bentuk jamak dari buddhi. Kata ini sering diucapkan dalam bahasa Indonesia budi, yang berarti hal-hal yang berkaitan dengan budi dan akal manusia. ${ }^{9}$ Kemudian, Koentjaraningrat menyatakan bahwa menurut ilmu antropologi, kebudayaan adalah keseluruhan sistem gagasan, tindakan, dan hasil karya manusia dalam kehidupan masyarakat yang dijadikan milik diri manusia dari belajar. ${ }^{10}$

Alfred Kroeber dan Clyde Kluckhon, dalam Suwardi Hasan, yang melakukan kompilasi 164 mengenai definisi budaya, mengatakan bahwa kata budaya umumnya digunakan dalam tiga pengertian mendasar. Pertama, keunggulan cita rasa dan selera terhadap kesenian dan kemanusiaan yang biasanya disebut budaya tinggi (excellence of taste in the fine arts and bumanities, also known as high culture). Kedua, polapola pengetahuan manusia, kepercayaan, dan kebiasaan yang terintegrasi yang tergantung pada kapasitas pemikiran simbolis dan pembelajaran sosial (an integrated pattern of human knowledge, belief, and behavior that depends upon the capacity for symbolic thought and social learning). Ketiga, seperangkat tingkah laku, nilai, tujuan, dan tindakan yang didalami bersama yang mencirikan terjadinya lembaga, organisasi,

\footnotetext{
8 Prasetijo, Adi, Serah Jajah dan Perlawanan yang 'lersisa: Etnografi Orang Rimba di Jambi, Jakarta: Wedatama Widya Sastra. h. 61

9 Suwardi Hasan, Sandi, Pengantar Cultural Studies, Yogyakarta, ArRuzz Media, 2011, h.14

10 Koentjaraningrat, Pengantar Ilmu Antropologi, Jakarta: Rineka Cipta, 2009, h. 144.
} 
dan kelompok (the set of shared attitudes, values, goals, and practices that characterizes and institution, organization or group). ${ }^{11}$

Kebudayaan mempunyai fungsi yang sangat besar bagi manusia dan masyarakat. Bermacam kekuatan yang harus dihadapi masyarakat dan anggota-anggotanya seperti kekuatan alam, maupun kekuatan-kekuatan lainnya di dalam masyarakat itu sendiri tidak selalu baik baginya. Selain itu, manusia dan masyarakat memerlukan pula kepuasan, baik dalam bidang spritual maupun material. Kebutuhan-kebutuhan masyarakat tersebut di atas untuk sebagian besar dipenuhi oleh kebudayaan yang bersumber pada masyarakat itu sendiri. ${ }^{12}$

\section{Metodologi Penelitian \\ 1. Metode Penelitian}

Untuk mengungkap nilai-nilai kearifan lokal dalam budaya Orang Rimba, peneliti menggunakan metode penelitian deskriptif kualitatif karena metode ini merupakan upaya memahami berbagai konsep yang ditemukan dalam proses penelitian. Penelitian kulatitatif adalah metode penelitian yang berlandaskan pada filsafat postpositivisme, digunakan untuk meneliti pada kondisi obyek yang alamiah, (sebagai lawannya eksperimen) di mana peneliti adalah sebagai instrumen kunci, pengambilan sampel sumber data dilakukan secara purposive dan snowball, teknik pengumpulan data dengan trianggulasi (gabungan), analisis data bersifat induktif/kualitatif, dan hasil penelitian kualitatif lebih menekankan makna dari generalisasi. ${ }^{13}$ Sementara itu, Taylor dan Bogdan dalam Susanti Hendarso mengemukakan bahwa penelitian kualitatif diartikan sebagai penelitian yang menghasilkan data deskriptif mengenai kata-kata lisan maupun tertulis, dan tingkah laku yang diamati dari orang-orang yang diteliti. ${ }^{14}$

\section{Teknik Pengumpulan Data}

Untuk memperoleh data dalam menjawab pertanyaan penelitian, maka peneliti menggunakan beberapa teknik pengumpulan

\footnotetext{
11 Suwardi Hasan, Sandi, Pengantar Cultural Studies, Jokjakarta: ArRuzz Media, 2011, h.14.

12 Soekanto, Soerjono, Sosiologi Suatu Pengantar, Jakarta: Raja Grafindo Persada, 2010, h.155

13 Sugiyono, Metode Penelitian Pendidikan, Alfabeta, Bandung, 2009, h. 15.

14 Susanti Hendarso, Penelitian Kualitatif; Sebuah Pengantar, Jakarta: Raja Grafindo Persada. 2010, h.166.
}

data penelitian, yaitu observasi, wawancara, dan studi dokumentasi.

Observasi dilakukan untuk memperoleh data berupa gambaran yang ada di lapangan, baik dalam bentuk sikap, tindakan, pembicaraan, interaksi interpersonal, dan lain-lain. Untuk itu observasi dilakukan dalam bentuk pengamatan yang tidak berstruktur, dalam arti dilakukan dengan mengikuti alur situasi dan kondisi wilayah pengamatan, mengalir dan larut dalam aktivitas yang terjadi di lapangan. ${ }^{15}$ Observasi tidak terstruktur adalah observasi yang tidak dipersiapkan secara sistematis tentang apa yang akan diamati. Dalam melakukan pengamatan, peneliti tidak menggunakan isntrumen yang telah baku, tetapi hanya berupa rambu-rambu pengamatan. ${ }^{16}$ Observasi dalam penelitian ini diarahkan pada praktik kearifan lokal pada Orang Rimba, Kecamatan Air Hitam, Kabupaten Sarolangun, antara lain budaya Melangun, Seloko, Mantera, Besale. Dalam hubungannya dengan pengelolaan sumber daya alam, peneliti melakukan observasi terhadap Hompongan, Tanah Peranakan, Tanah Bedewa-dewa, Bento Benuaran, Pohon Sialang, Pohon Setubung, Pohon Tenggeris, dan Rumah Godong.

Wawancara dilakukan untuk mendapatkan informasi yang tidak dapat diperoleh melalui observasi atau teknik pengumpulan data lainnya. Hal ini lebih disebabkan karena keterbatasan peneliti untuk melakukan pengamatan secara keseluruhan. Di samping itu tidak semua data diperoleh melalui pengamatan, sehingga mengharuskan peneliti untuk melakukan wawancara kepada responden penelitian. Untuk memperoleh data-data penting, peneliti berusaha mencari nara sumber dari kalangan tokoh terkemuka yang ada di tengah masyarakat Orang Rimba, Kecamatan Air Hitam, Kabupaten Sarolangun. Nara sumber tersebut merupakan tokoh-tokoh yang memiliki pemahaman yang mendalam mengenai budaya Orang Rimba.

Data dalam penelitian ini juga diperoleh melalui studi dokumen. Studi dokumen merupakan pelengkap dari penggunaan

15 Arif, Muhamad, Model Kerukunan Sosial Pada Masyarakat Multikultural Cina Benteng (Kajian Historis dan Sosiologis), Jurnal Sosio Didaktika, 2014, h.57.

16 Sugiyono, Metode Penelitian Pendidikan, Bandung: Alfabeta, 2009, h. 313 
metode observasi dan wawancara. Dokumen merupakan catatan peristiwa yang sudah berlalu. Dokumen bisa berbentuk tulisan, gambar, atau karya-karya monumental dari seseorang. ${ }^{17}$ Studi dokumentasi diperlukan untuk menggali informasi penting tentang sejarah Orang Rimba, asal-usul Orang Rimba, dan lain sebagainya.

\section{Temuan Penelitian}

Melalui observasi, wawancara, dan studi dokumentasi, diperoleh hasil penelitian mengenai budaya Orang Rimba di Kecamatan Air Hitam, Kabupaten Sarolangun, Provinsi Jambi, terutama menyangkut kearifan lokal yang terkandung di dalamnya, seperti uraian berikut ini.

\section{Budaya Melangun}

Orang Rimba mengenal kebiasaan yang unik dan berbeda dari suku yang lainnya. Mereka mengenal istilah melangun. Melangun merupakan tradisi meninggalkan genah (tempat tinggal) secara bersama-sama menuju ke genah (tempat tinggal) baru jika ada anggota keluarga meninggal dunia di tempat tinggal tersebut. ${ }^{18}$ Mereka harus meninggalkan ladang, hasil ladang, dan rumah untuk pindah ke tempat lain. Biasanya daerah yang dituju merupakan daerah bekas daerah garapan mereka dahulu yang telah lama ditinggalkan atau tempat-tempat lain yang dianggap mempunyai sumber makanan yang cukup melimpah, baik nabati maupun hewani.

Upacara melangun biasanya dimulai ketika salah satu anggota keluarga dalam kelompok dianggap menunjukkan tanda-tanda akan meninggal karena sakit keras. Anggota yang sakit keras segera diungsikan ke tempat lain dalam sebuah pondok dengan ditunggui keluarga dekatnya (ayah, ibu, anak, dan saudara kandung). Anggota keluarga lain yang masih dalam kelompok segera mempersiapkan melangun. Jika yang bersangkutan meninggal, maka mulailah upacara melangun. Dalam bepergian tersebut seluruh anggota keluarga wanita dan anak-anak meratop sejadi-jadinya. Meratop adalah menangis secara histeris sambil menyebut-nyebut nama orang yang meninggal. ${ }^{19}$
Seorang tokoh Orang Rimba yang sekarang sudah memeluk agama Islam, Jailani, menjelaskan bahwa di zaman dahulu melangun dilakukan selama 3 (tiga) tahun. Sekarang tradisi melangun hanya dilakukan selama 3 (tiga) bulan saja. Menurut keyakinan mereka melangun dilakukan untuk menghilangkan rasa sedih karena kehilangan anggota keluarga yang telah meninggal dunia. Tradisi ini masih dilakukan bagi Orang Rimba setiap ada saudara atau kerabat mereka yang meninggal dunia.

\section{Seloko dan Mantera}

Kehidupan Orang Rimba sangat dipengaruhi oleh aturan-aturan hukum yang sudah diterapkan dalam bentuk seloko-seloko (istilah, pepatah yang menjadi aturan adat) yang secara tegas dijadikan pedoman hidup oleh para pemimpin, khususnya Temenggung dalam membuat suatu keputusan. Seloko juga menjadi pedoman dalam bertutur kata serta bertingkah laku dalam kehidupan bermasyarakat Orang Rimba.

Adapun bentuk-bentuk seloko itu antara lain: (a) Bak emas dengan suaso (perbedaan antara nilai yang mahal dan murah), (b) Bak tali bepintal tigo (kebersamaan menjadi kekuatan), (c) Yang tersurat dan tersirat (sudah dipegang dan dimiliki), (d) Mengaji di atas surat (mempunyai dasar/ aturan), (e) Banyak daun tempat beteduh (banyak tempat mengadu), (f) Meratap di atas bangkai (menyampaikan keluh kesah), (g) Dak teubah anjing makan tai (kebiasaan yang sulit di ubah), (h) Di mano biawak terjun di situ anjing telulung (di mana kita berbuat salah di situ adat yang dipakai) (i) Di mano bumi dipijak di situ langit dijunjung (di mana kita berada, di situ adat yang kita junjung, kita harus pandai-pandai menyesuaikan diri), (j) Bini sekato laki dan anak sekato Bapak (bahwa dalam urusan keluarga sangat menonjol peran seorang laki-laki atau Bapak), dan (k) Titian galing tenggung negeri (tidak ke sini juga tidak kesana/ labil/ bimbang/ ragu).

Adapun manfaat dari Seloko dan Mantera ini adalah untuk menegakkan hukum bagi orangorang yang melanggar peraturan. Seloko di atas masih berlaku dan selalu digunakan dalam kehidupan sehari-hari termasuk jika ada Orang Rimba yang melanggar hukum. 


\section{Besale}

Besale adalah kegiatan yang dilakukan oleh Orang Rimba untuk memanggil dewa mereka agar hadir dalam acara pengobatan dan pernikahan Orang Rimba. ${ }^{20}$ Dalam kegiatan besale ini terdapat satu seloko, yaitu ado rimbo ado bungo, ado bungo ado dewa. Maksudnya ialah bunga dapat menghadirkan dewa, dan bunga itu menjadi syarat sah bagi pasangan yang hendak menikah. Bunga yang bisa digunakan dalam besale itu banyak sekali, boleh menggunakan bunga apa saja, asalkan bunga tersebut berasal dari rimba. Tanpa bunga menikahnya tetap sah tetapi belum diakui oleh Tamenggung karena syaratnya kurang. Selain untuk proses pernikahan, kegiatan besale juga biasa dilakukan untuk kegiatan lain, misalnya untuk mengobati orang sakit gigi, maka dipanggillah dewa dengan cara mengambil bunga. Bunga yang digunakan berobat tidaklah sama dengan bunga untuk ritual pernikahan.

\section{Budaya Pelestarian Alam}

Dalam pengelolaan sumberdaya alam, Orang Rimba mengenal wilayah peruntukan, seperti adanya hompongan, Tanob Peranokon, rimba, ladang, sesap, belukor dan benuaron. Peruntukan wilayah merupakan rotasi penggunaan tanah yang berurutan dan dapat dikatakan sebagai sistem suksesi sumber daya hutan mereka. Hutan yang disebut rimba oleh mereka, diolah sebagai ladang sebagai suplai makanan pokok (ubi kayu, padi ladang, ubi jalar), kemudian setelah ditinggalkan berubah menjadi sesap.

\section{a. Hompongan}

Hompongan dalam bahasa rimba berarti 'bendungan/batas'. Hompongan ini berbentuk ladang yang sambung-menyambung antara satu dan yang lain di daerah perbatasan Taman Nasional Bukit Duabelas untuk menghambat proses perambahan hutan yang dilakukan masyarakat luar. ${ }^{21}$ Kholis juga menyatakan bahwa hompongan adalah lahan yang bentuknya memanjang dan ditanami karet dan tanaman lainnya. pembuatan hompongan ini menjadi batas sekaligus penyangga hutan Taman Nasional Bukit Duabelas. Warga luar atau perusahaan dilarang keras membuka hutan

20 Ibrahim, Kehidupan Suku Anak Dalam di Kecamatan Air Hitam Kabupaten Sarolangun, Jurnal Antologi Geografi Jurusan Pendidikan Geografi Universitas Pendidikan Indonesia, Volume 1, Nomor 3, Edisi Desember 2013.

21 Adi Prasetijo, Serah Jajah dan Perlawanan yang Tersisa: Etnografi Orang Rimba di Jambi, Jakarta, Wedatama Widya Sastra.h. 200. melewati hompongan tersebut. ${ }^{22}$

Hompongan ini dibuat oleh kelompok Pak Tarib untuk menjaga kawasan Taman Nasional Bukit Duabelas dengan membuat lading perkebunan karet yang sambung menyambung antara satu dengan yang lainnya yang digunakan sebagai pembatas antara ladang masyarakat luar dengan kawasan Taman Nasional Bukit Duabelas. Hompongan berfungsi untuk menghambat proses perambahan hutan yang dilakukan oleh masyarakat luar.

Manfaat dari pembuatan pagar atau tanda milik tanah tersebut untuk melindungi hutan dari perusakan yang dilakukan oleh orang-orang yang tidak bertanggung jawab. Karena jika hutan dirusak, maka akan mudah terjadinya bencana alam. Jika bencana terjadi, maka masyarakat sekitar Taman Nasional Bukit Duabelas akan mendapat musibah. Kondisi hompongan sekarang masih dipakai oleh Orang Rimba karena masyarakat luar merasa segan dan malu untuk mengambil tanah yang sudah dibuat hompongan.

\section{b. Tanah Peranakan}

Tanah Peranakan adalah tanah yang sudah dipilih oleh orang pintar atau dukun dalam bahasa Orang Rimba, yaitu tanah yang sudah terbebas dari gangguan roh jahat yang ingin mengganggu. ${ }^{23}$ Tanah ini diperuntukkan bagi perempuan yang hendak melahirkan. Jadi para ibu-ibu Orang Rimba diharuskan melahirkan di atas tanah tersebut. Tanah peranakan ini tidak boleh gunakan untuk membuka ladang pertanian apalagi dirusak. Tanah peranakan dianggap sebagai tanah yang dapat membawa keberuntungan atau biasa disebut mujur dalam bahasa Orang Rimba, baik bagi ibu yang melahirkan maupun bagi anak yang dilahirkan. Sampai saat ini tanah peranakan masih dijaga dengan baik oleh Orang Rimba.

\section{c. Tanah Badewa-dewa}

Tanah badewa-dewa maksudnya adalah tanah yang dipercayai oleh Orang Rimba bahwa di dalamnya dihuni oleh dewa-dewa. ${ }^{24}$ Tanah ini harus tetap dijaga dan tidak boleh dirusak. Kegunaannya adalah untuk tempat pemujaan

\footnotetext{
22 Kholis, Hompongan Kearifan Lokal Untuk Kearifan Global, dapat dilihat secara online di http://www.metrojambi.com/v1/daerah/3880-hompongan-kearifan-lokal-untuk-kearifan-global.html, 2012.

23 Ibrahim, Kehidupan Suku Anak Dalam di Kecamatan Air Hitam Kabupaten Sarolangun, Jurnal Antologi Geografi Jurusan Pendidikan Geografi Universitas Pendidikan Indonesia, Volume 1, Nomor 3, Edisi Desember 2013. h. 7 24 Ibid. h. 7
} 
agar mereka selalu diberikan pertolongan, rizki, dan dikeluarkan dari segala macam permasalahan. Orang Rimba sangat menjaga keutuhan dari tanah tersebut. Hingga sekarang tanah badewa-dewa masih ada karena mereka selalu menjaganya.

\section{d. Bento Benuaran}

Bento benuaran ialah tanah pusaka peninggalan nenek moyang terdahulu. Tanah pusaka ini berisi pohon-pohon yang berbuah seperti pohon durian, pohon kemang, pohon rambutan, dan lain sebagainya yang berada di rimba. Orang Rimba saling berbagi tugas untuk menjaganya. Jika tanah bento benuaran ini dirusak, maka pelaku perusakan tersebut harus berurusan dengan tamenggung dan akan dikenakan sanksi yang setimpal. Tanah pusaka bento benuaran ini bukan merupakan milik perorangan, melainkan milik bersama, sehingga siapapun boleh memanfaatkannya dengan mengambil buah-buahannya secukupnya saja.

Kondisi tanah pusaka bento benuaran di rimba hingga penelitian ini dilaksanakan tetap terjaga. Bento benuaran juga tidak hanya dinikmati oleh Orang Rimba, tetapi juga masyarakat desa di sekitar lokasi Orang Rimba juga merasakan hasil dari peninggalan pusaka bento benuaran tersebut.

\section{e. Pohon Sialang}

Yang dimaksud dengan Pohon Sialangadalah pohon yang biasa dihinggapi lebah penghasil madu. Biasanya pohon ini hanya tumbuh di rimba, karena lebah lebah suka berada di tempat yang sepi dan berada di pohon besar. Pohon yang biasa dihinggapi lebah madu itu adalah pohon rengas dan pohon aro. Pada masa sekarang, madu hutan sudah sangat sulit untuk didapat, karena pohon rengas dan pohon aro sudah banyak yang ditebang oleh masyarakat. Orang Rimba sangat mengecam keras kegiatan penebangan dan perusakan hutan karena kerugian yang diderita akibat pengrusakan hutan itu sangat banyak, salah satu di antaranya adalah sulitnya mencari madu hutan.

Untuk mencegah pengrusakan dan penebangan pohon di hutan Taman Nasional Bukit Duabelas, mereka secara bersama-sama menjaga hutan termasuk menjaga dan merawat Pohon Sialang agar tidak habis dan musnah dari hutan. Sehingga Madu Sialang, atau biasa dikenal dengan istilah Madu Hutan, tetap mudah di dapat dan bisa dinikmati oleh semua kalangan.

\section{f. Pohon Setubung}

Pohon Setubung adalah pohon yang biasanya bagi Orang Rimba berguna untuk membuat pagar bali bayi yang baru lahir. Bali bayi yang baru lahir ditanam, kemudian ditancapkan di atasnya tiga potong batang setubung di sekeliling bali bayi, bentuknya seperti tungku untuk memasak nasi. Pohon setubung ini sangat dipelihara oleh Orang Rimba. Jika ada yang menebang dan merusak pohon ini maka mereka akan didenda dengan 60 helai kain.

\section{g. Pohon Tenggeris}

Pohon Tenggeris berfungsi sebagai bahan dalam ritual pemberian nama kepada anak Orang Rimba yang baru dilahirkan. Cara penggunaannya adalah kulit Pohon Tenggeris diambil seperlunya seukuran lutut orang lakilaki dewasa pada umumnya. Kemudian kulit kayu itu dihaluskan, lalu ditempelkan pada dahi bayi tersebut sambil menyebutkan nama bayi itu. Misalnya, orang tuanya berkata, "Saya sahkan nama kamu sekarang Basiring". Mulai saat itu bayi itu sah bernama Basiring. Adapun tujuannya adalah agar anak tersebut kelak menjadi anak yang baik, berbakti kepada kedua orang tuanya, dan berguna bagi keluarganya. Dalam bahasa rimba mereka biasa juga menambahkan dengan kata-kata "Kerailah kayu Tengeris kerailah semangat anak awak" (Sebagaimana pohon Tenggeris yang keras, begitulah kerasnya semangat anak saya kelak). Sampai saat ini populasi pohon ini masih banyak. Pohon Tenggeris ini pun sangat dirawat dan dijaga dengan baik. Apabila ada yang merusaknya maka sanksinya adalah didenda dengan 60 helai kain.

\section{Rumah Godong}

Rumah godong ialah rumah adat bagi Orang Rimba. Rumah godong ini hanya ada di ladang. Dan kamarnya pun ditata rapi. Anak laki-laki tidak boleh bercampur tempat tidur dengan anak perempuan, walaupun saudara kandungnya sendiri. Mereka mempunyai kamar masingmasing. Kegunaan dari rumah godong ini adalah untuk berkumpul dan bermusyawarah bersama dalam menyelasaikan suatu masalah.

\section{E. Pembahasan}

Tidak semua budaya Orang Rimba sesuai dengan nilai-nilai yang dianut oleh masyarakat 
Indonesia pada umumnya. Orang Rimba mengenal istilah melangun, yaitu kegiatan pindah dari tempat yang lama menuju tempat yang baru selama kisaran waktu antara 3 (tiga) sampai dengan 5 (lima) bulan setiap ada di antara anggota keluarganya meninggal dunia. Tradisi melangun ini bagi sebagian Orang Rimba masih dipertahankan hingga sekarang. Tradisi ini sangat mengganggu aktivitas Orang Rimba itu sendiri, seperti bagi anak rimba yang sedang bersekolah harus libur dalam jangka waktu yang sangat panjang karena ikut orang tuanya melangun. Kegiatan pertanian harus ditinggalkan, hubungan perdagangan dengan masyarakat Melayu sekitarnya jadi terputus sementara waktu.

Di sisi lain, dalam berperilaku dan berbahasa, Orang Rimba masih mengedepankan nilai sopan santun yang sudah diwariskan oleh nenek moyangnya secara turun temurun. Dalam berkata-kata, Orang Rimba sering kali menggunakan pantun yang di dalam rimba biasa disebut dengan seloko. Penggunaan seloko dilakukan agar orang yang sedang diajak bicara tidak langsung tersinggung jika perkataan itu sebenarnya menyindir atau menyinggung perasaan.

Dalam kegiatan besale, terdapat nilai yang perlu diketahui bahwa kegiatan ini selalu dilaksanakan dengan mengharuskan ketersediaan berbagai jenis kembang. Ini mengisyaratkan bahwa hutan dan tumbuhan harus terus terjaga agar tanaman kembang/ bunga selalu tersedia di dalam rimba.

Nilai kearifan lokal yang sangat penting untuk diteladani oleh semua kalangan, adalah tradisi Orang Rimba dalam menjaga kelestarian alam. Dalam menjaga kelestarian alam Orang Rimba tidak boleh merusak hutan sembarangan karena mereka memiliki larangan-larangan di dalam hutan. Larangan itu antara lain karena adanya tanah peranakan dan tanah bedewa-dewa yang merupakan wilayah hutan yang tidak boleh dirambah dan ditebang apalagi dirusak. Karena Orang Rimba menganggap bahwa wilayah tersebut memilki nilai yang sakral dan memiliki fungsi yang sangat tinggi. Kemudian ada pohon sialang, setubung, dan pohon tenggeris yang tidak boleh ditebang di dalam hutan karena pohon tersebut memiliki manfaat yang sangat besar bagi Orang Rimba. Misalkan pohon sialang memiliki fungsi sebagai tempat lebah penghasil madu untuk bersarang.

\section{F. Penutup}

Berdasarkan paparan di atas, maka dapat diambil beberapa kesimpulan sebagai berikut. Pertama, Orang Rimba sangat menggantungkan hidupnya kepada hutan. Bahkan Orang Rimba itu sendiri merupakan bagian dari hutan di Taman Nasional Bukit Duabelas (TNBD) Kabupaten Sarolangun, Provinsi Jambi. Kedua, budaya melangun sangat mengganggu kehidupan Orang Rimba, misalnya bagi anak-anak yang sedang bersekolah harus libur dalam jangka waktu yang sangat panjang karena ikut orang tuanya melangun, aktivitas pertanian harus ditinggalkan, dan hubungan perdagangan dengan masyarakat Melayu sekitarnya jadi terputus sementara waktu. Ketiga, implementasi nilai-nilai kearifan lokal dalam budaya Orang Rimba antara lain kegigihan dan konsistensi Orang Rimba dalam menjaga dan melestarikan hutan. Dalam melestarikan hutan Orang Rimba mengenal istilah pembuatan bompongan, pemeliharaan pohon setubung, pohon sialang, bento benuaran dan pohon tenggeris. Selain itu mereka juga sangat menjaga dan merawat berbagai jenis bunga yang hidup dan tumbuh di dalam hutan yang biasa mereka gunakan dalam kegiatan besale.

\section{Daftar Pustaka}

Arif, Muhamad. 2014. Model Kerukunan Sosial Pada Masyarakat Multikultural Cina Benteng (Kajian Historis dan Sosiologis). Jurnal Sosio Didaktika Volume I Nomor 1 Tahun 2014.

BPS. 2014. online, di http://www.bps.go.id/ download_file/IP.pdf.

Haviland, William A. 1985. Antropologi; jilid 2 Jakarta: Erlangga.

Ibrahim. 2013. Kebidupan Suku Anak Dalam di Kecamatan Air Hitam Kabupaten Sarolangun. Jurnal Antologi Geografi Jurusan Pendidikan Geografi Universitas Pendidikan Indonesia. Volume 1 Nomor 3 Tahun 2013. 
Jasin, Maskoeri. 2002. Ilmu Alamiah Dasar. Jakarta: Raja Grafindo Persada.

Johan. 2003. Organisasi Sosial dan Kebudayaan Kelompok Minoritas Indonesia, Makalah pada Program Studi Indonesia Kerjasama Pendidikan Tersier Indonesia - Australia. Yogyakarta: Universitas Gadjah Mada.

Kholis. 2012. Hompongan Kearifan Lokal Untuk Kearifan Global, dapat dilihat secara online di http://www.metrojambi.com/v1/ daerah/3880-hompongan-kearifan-lokaluntuk-kearifan-global.html.

Koentjaraningrat. 2009. Pengantar Ilmu Antropologi. Jakarta: Rineka Cipta.

Nasruddin, dkk. 2011. Kearifan Lokal di Tengah Modernisasi. Jakarta. Pusat Penelitian dan Pengembangan Kebudayaan Badan Pengembangan Sumber Daya Kebudayaan dan Pariwisata Kementerian Kebudayaan dan Pariwisata Republik Indonesia.
Prasetijo, Adi. 2011. Serah Jajah dan Perlawanan yang Tersisa: Etnografi Orang Rimba di Jambi. Jakarta: Wedatama Widya Sastra.

Soekanto, Soerjono. 2010. Sosiologi Suatu Pengantar. Jakarta: Raja Grafindo Persada.

Sugiyono. 2009. Metode Penelitian Pendidikan. Bandung: Alfabeta.

Sumaatmadja, Nursid. 1981. Studi Geografi Suatu Pendekatan dan Analisa Keruangan. Bandung: Alumni.

Susanti Hendarso. 2010. Penelitian Kualitatif; Sebuah Pengantar. Jakarta: Rajawali Press.

Suwardi Hasan, Sandi. 2011. Pengantar Cultural Studies. Yogyakarta: Ar-Ruzz Media.

Undang-undang RI No. 32 Tahun 2009 Tentang Perlindungan dan Pengelolaan Lingkungan Hidup. 
